\title{
Data Mining untuk Klasifikasi Penderita Kanker Payudara Berdasarkan Data dari University Medical Center Menggunakan Algoritma Naïve Bayes
}

\author{
Ibnu Ramadhan, Kurniawati \\ Jurusan Sistem Informasi, Fakultas Ilmu Komputer, Universitas Darwan Ali, Kalimantan Tengah, Indonesia \\ E-mail : ${ }^{1}$ ibn.rmdn19@gmail.com, ${ }^{2}$ kurniawati.vivo@gmail.com \\ Submitted 20-12-2019; Accepted 21-01-2020; Published 15-02-2020
}

\begin{abstract}
Abstrak
Data penderita kanker payudara dari University Medical Center merupakan data tentang pasien yang mengidap kanker payudara berdasarkan ciri-ciri tertentu. Data ini memiliki informasi yang berlimpah sehingga dapat dilakukan data mining dengan tujuan menggali informasi lebih dalam yang tentu saja bisa bermanfaat ke depannya. Class data sendiri terbagi menjadi 2 kelompok yaitu class kambuh dan tidak kambuh. Teknik yang digunakan dalam penelitian ini yaitu Klasifikasi dengan menggunakan algoritma Naive Bayes. Naive Bayes adalah teknik prediksi dengan basis probabilistik sederhana yang berdasar pada implementasi aturan bayes dengan asumsi independensi yang kuat pada fitur. Tools yang digunakan untuk menemukan nilai akurasi adalah RapidMiner 9.3. Atribut data terdiri dari Class, Age, Menopause, Tumor-Size, InvNodes, Node-Caps, Deg-Malig, Breast, Breast-Quad dan Irradiant. Dari segi metode, penelitian ini menggunakan metode CRISP-DM (Cross Industry Standard Process for Data Mining). Penelitian ini digunakan sebagai informasi dalam pengambilan keputusan untuk menentukan kebijakan yang diambil dalam menangani pasien penderita kanker payudara.
\end{abstract}

Kata Kunci: Class, Age, Menopause, Tumor-Size, Inv-Nodes, Node-Caps, Deg-Malig, Breast, Breast-Quad, Irradiant, Naive Bayes, Klasifikasi, Kanker Payudara.

\begin{abstract}
The breast cancer sufferers data from the University Medical Center is data about patients suffering from breast cancer based on certain characteristics. This data has abundant information so that data mining can be done with the aim of digging deeper information which of course can be useful in the future. The data class itself is divided into 2 groups: recurrence and non-relapse classes. The technique used in this study is classification using the Naive Bayes algorithm. Naive Bayes is a simple probabilistic prediction technique based on the implementation of Bayes rules with a strong assumption of independence on features. The tool used to find accuracy values is RapidMiner 9.3. Data attributes consist of Class, Age, Menopause, Tumor-Size, Inv-Nodes, Node-Caps, Deg-Malig, Breast, Breast-Quad and Irradiant. In terms of methods, this study uses the CRISP-DM (Cross Industry Standard Process for Data Mining) method. This research is used as information in making decisions to determine policies taken in dealing with patients with breast cancer.
\end{abstract}

Keywords: Class, Age, Menopause, Tumor-Size, Inv-Nodes, Node-Caps, Deg-Malig, Breast, Breast-Quad, Irradiant, Naive Bayes, Classification, Breast Cancer.

\section{PENDAhULUAN}

Teknologi informasi terus mengalami kemajuan dari zaman ke zaman. Teknologi informasi sendiri sudah memberikan berbagai informasi serta data yang bermanfaat bagi kehidupan masyarakat pada umumnya. Informasi yang dihasilkan sudah mencakup seluruh bidang kehidupan manusia mulai dari ekonomi, politik, sejarah, sosial, kesehatan dan sebagainya. Teknologi juga memberikan peran dalam kemajuan berbagai institusi, salah satunya instansi kesehatan. Data yang dihasilkan di bidang kesehatan bisa berupa data mengenai penyakit yang dianggap mematikan seperti kanker, yang tentu saja data ini dapat dimanfaatkan untuk menggali informasi lebih dalam terkait kanker itu sendiri, baik untuk pengobatan ataupun pencegahan terhadap pasien yang belum dan atau sudah mengalami penyakit kanker.

Dikutip dari situs resmi CNN pada tahun 2018, jumlah penderita kanker di seluruh dunia terus meningkat secara signifikan. Laporan terbaru yang dirilis oleh International Agency for Research on Cancer, WHO (Organisasi Kesehatan Dunia), mengestimasi terdapat 18,1 juta kasus kanker baru dan 9,6 juta kematian yang terjadi pada tahun 2018. Serangan kanker yang masif ini diprediksi oleh $\mathrm{WHO}$ akan menjadi penyebab kematian nomor satu di dunia pada akhir abad ini. Hasil analisa ini didapat setelah peneliti mereka menganalisis data dari 185 negara di dunia dengan fokus pada 36 jenis kanker. Beberapa jenis kanker yang disebutkan seperti kanker paru, kolorektal, lambung, hati dan payudara.

Semua informasi yang disebutkan di atas dapat dimanfaatkan untuk mengetahui pola baru dari sebuah data dengan cara melakukan pengolahan atau penggalian data. Pola baru ini dapat digunakan untuk tujuan yang bermanfaat misalnya pengklasifikasian data penderita penyakit kanker berdasarkan kambuh atau tidak kambuhnya penyakit tersebut. Pengetahuan ini dapat membantu pihak medis dalam hal penanganan pasien untuk meminimalisir jumlah penderita kanker yang mengalamai kambuh penyakit tersebut.

Berdasarkan hasil paparan dari $W H O$ serta data yang diperoleh dari University Medical Center berupa dataset pengidap kanker payudara dengan jumlah record data sebanyak 186 data, penulis akan melakukan penelitian secara ilmiah menggunakan metode klasifikasi dengan algoritma Naive Bayes guna mengetahui nilai perbandingan antara kambuh atau tidak kambuhnya penyakit tersebut. Hasil klasifikasi ini sendiri nantinya dapat dimanfaatkan untuk penangan pasien guna mengurangi jumlah pasien yang sering mengalami kambuh penyakit kanker. 
Penelitian ini akan melakukan pengklasifikasian berdasarkan data yang didapat dari University Medical Center dengan atribut data : Class, Age, Menopause, Tumor-Size, Inv-Nodes, Node-Caps, Deg-Malig, Breast, Breast-Quad dan Irradiant.

Tujuan dari penelitian ini adalah sebagai berikut :

a. Mengklasifikasi data pengidap kanker payudara berdasarkan data yang diperoleh dari University Medical Center.

b. Mendapatkan akurasi yang tepat dalam melakukan klasifikasi mengenai data pengidap kanker payudara yang diperoleh dari University Medical Center dengan menggunakan metode Naive Bayes.

\section{METODE PENELITIAN}

\subsection{Data Mining}

Data mining merupakan proses yang menggunakan teknik statistik, matematika, kecerdasan buatan, dan machine learning untuk mengekstrasi dan mengidentifikasi informasi yang bermanfaat dan pengetahuan yang terkait dari berbagai database besar[1].

\subsection{Pengelompokan Data Mining}

Menurut Larose, data mining dibagi menjadi beberapa kelompok berdasarkan tugas yang dapat dilakukan, yaitu[2]:

\section{a. Deskripsi}

Terkadang peneliti dan analisis secara sederhana ingin mencoba mencari cara untuk menggambarkan pola dan kecendrungan yang terdapat dalam data.

b. Estimasi

Estimasi hampir sama dengan klasifikasi, kecuali variabel target estimasi lebih ke arah numerik dari pada ke arah kategori.

c. Prediksi

Prediksi hampir sama dengan klasifikasi dan estimasi, kecuali bahwa dalam prediksi nilai dari hasil akan ada di masa mendatang.

d. Klasifikasi

Dalam klasifikasi, terdapat target variabel kategori.

e. Pengklusteran

Pengklusteran merupakan suatu metode untuk mencari dan mengelompokkan data yang memiliki kemiripan karakteriktik (similarity) antara satu data dengan data yang lain. Clustering merupakan salah satu metode data mining yang bersifat tanpa arahan (unsupervised).

f. Asosiasi

Tugas asosiasi dalam data mining adalah menemukan atribut yang muncul dalam suatu waktu.

\subsection{Metode Data Mining}

Menurut Larose, data mining mempunyai 6 fase CRISP-DM ( Cross Industry Standard Process for Data Mining)[3]. Adapun 6 fase tersebut diantaranya sebagai berikut :

a. Fase Pemahaman Bisnis ( Business Understanding Phase)

b. Fase Pemahaman Data ( Data Understanding Phase)

c. Fase Pengolahan Data ( Data Preparation Phase)

d. Fase Pemodelan (Modeling Phase)

e. Fase Evaluasi ( Evaluation Phase )

f. Fase Penyebaran (Deployment Phase)

\subsection{Algoritma Naive Bayes}

Naive Bayes adalah pengklasifikasian statistik yang dapat digunakan untuk memprediksi probabilitas keanggotaan suatu class. Naive Bayes didasarkan pada teorema Bayes yang memiliki kemampuan klasifikasi serupa dengan decision tree dan neural network. Naive Bayes terbukti memiliki akurasi dan kecepatan yang tinggi saat diaplikasikan ke dalam database dengan data yang besar[4].

Formula umum Naive Bayes sendiri yaitu sebagai berikut[3] :

$$
\mathrm{P}(\mathrm{H} \mid \mathrm{X})=\mathrm{P}(\mathrm{X} \mid \mathrm{H}) \chi \mathrm{P}(\mathrm{H}) / \mathrm{P}(\mathrm{H})
$$

\subsection{RapidMiner}

RapidMiner adalah sebuah lingkungan machine learning data mining, text mining dan predictive analytics[5].

\section{ANALISA DAN PEMBAHASAN}




\subsection{Pemahaman Bisnis}

Merupakan tahap paling awal dari CRISP-DM untuk memahami tujuan awal dari sebuah penelitian.

a. Menentukan Tujuan Bisnis (Tujuan Data Mining)

Tujuan penelitian berdasarkan pengolahan data yang didapat dari University Medical Center yaitu untuk meminimalisir jumlah penderita kanker payudara yang sering mengalami kambuh penyakit. Tujuan pengolahan data sendiri dapat dijadikan dasar dalam pengambilan keputusan untuk mementukan penangan seperti apa yang akan diberikan kepada pasien yang sering mengalami kambuh penyakit.

b. Melakukan Penilaian Situasi

Tahap ini merupakan tahap untuk memahami tujuan penelitian serta menerjemahkannya ke dalam tujuan data mining.

c. Menentukan Strategi Awal Data Mining

Demi menerapkan tujuan dilakukannya data mining, maka strategi awal yang dilakukan yaitu mencari dataset penderita penyakit kanker melalui website resmi yang sudah disediakan.

\subsection{Pemahaman Data}

Data awal merupakan dataset pasien pengidap kanker payudara yang didapat dari University Medical Center berbentuk file dengan format .csv. Isi data sendiri berjumlah 286 record.

a. Pengumpulan Data Awal

Dataset pada penelitian ini merupakan sekumpulan data yang didapat dari University Medical Center dengan kelas data dibagi menjadi 2 kelompok yaitu kambuh dan tidak kambuh.

b. Mendeskripsikan Data

Dataset ini terdiri dari beberapa atribut diantaranya Class, Age, Menopause, Tumor-Size, Inv-Nodes, Node-Caps, Deg-Malig, Breast, Breast-Quad dan Irradiant.

c. Evaluasi Kualitas Data

Hasil evaluasi dataset ini yaitu banyak data yang tidak memiliki nilai (missing value) sehingga perlu dilakukan preprocessing data.

d. Pemilihan Atribut

Atribut data yang akan digunakan adalah keseluruhan atribut yang sudah dijelaskan sebelumnya.

\subsection{Persiapan Data}

Tahap ini merupakan serangkaian kegiatan untuk membangun dataset yang akan digunakan ke dalam alat pemodelan. Data mentah akan di cek ulang sebelum data tersebut dapat diimplementasikan ke dalam tools RapidMiner.

a. Seleksi Data

Melakukan seleksi data dengan melihat apakah ada data rusak atau tidak sehingga dari jumlah awal data yaitu 286 record data berubah menjadi 186 record data.

b. Pengolahan Data Mentah

Tahap ini merupakan tahap untuk memastikan bahwa data yang akan digunakan telah layak untuk dilakukan proses pengolahan.

d. Transformasi Data

Data dengan jenis numerikal diubah menjadi polynominal atau binominal. Hal ini dikarenakan teknik klasifikasi tidak dapat menerima data dengan tipe numerikal. Berikut ini contoh dataset yang sudah diubah jenis atau tipe datanya :

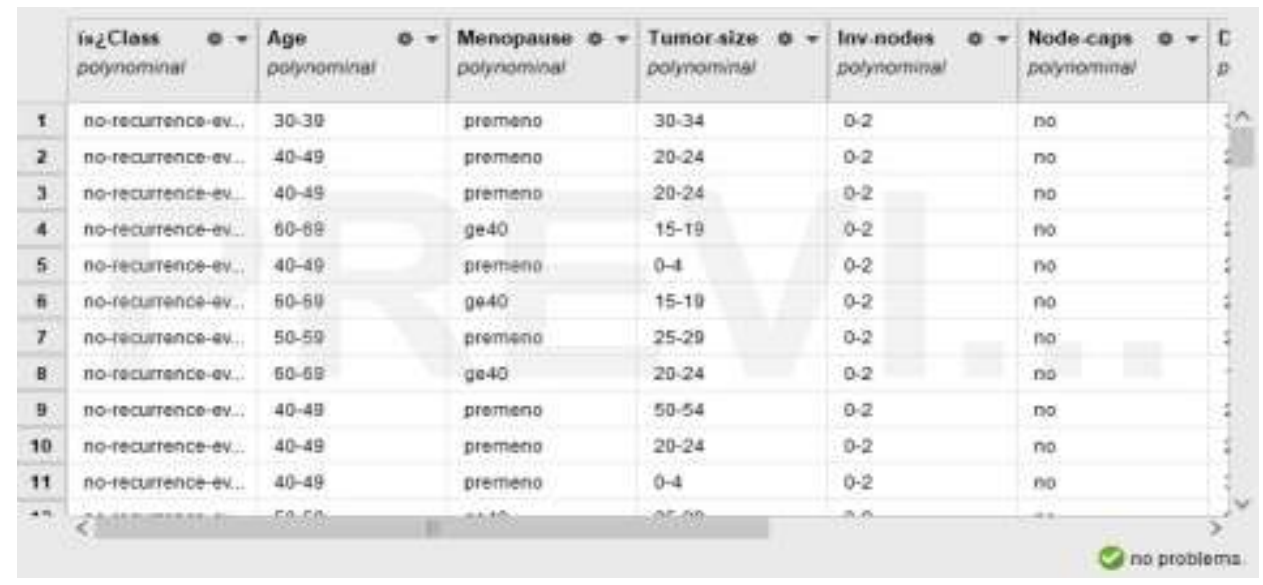

Gambar 1. Transformasi data 


\subsection{Pemodelan}

Pemodelan merupakan tahapan di mana peneliti melibatkan langsung teknik data mining yaitu dengan melakukan pemilihan teknik serta menetukan algoritma apa yang akan digunakan dalam pengolahan dataset ini nantinya.

a. Pemilihan Teknik Pemodelan

Tools yang akan digunakan adalah RapidMiner 9.3 dengan teknik yang dipilih yaitu klasifikasi. Atribut data berupa integer diubah terlebih dahulu menjadi binominal atau polynominal tergantung isi datanya seperti apa. Sementara itu metode yang digunakan yaitu Naive Bayes dengan cara menghitung $\mathrm{P}(\mathrm{Ci})$ untuk setiap atribut data. Dalam kasus dataset pada penelitian ini, atribut class terdiri dari 2 kelompok, yaitu "kambuh" dan "tidak kambuh". Atribut inilah yangmejadi patokan dalam perhitungan nantinya.

Kemudian tahap selanjutnya menghitung $\mathrm{P}(\mathrm{X} \mid \mathrm{Ci}), \mathrm{i}=1,2$ untuk setiap kelas atau atribut. Setelah itu bandingkan, jika $\mathrm{P}(\mathrm{X} \mid \mathrm{C} 1)$ $>\mathrm{P}(\mathrm{C} \mid \mathrm{X} 2)$ maka kesimpulannya $\mathrm{C} 1$ adalah kelas "kambuh". Jika sebaliknya maka kesimpulannya $\mathrm{C} 2$ adalah kelas "tidak kambuh".

b. Perhitungan Data Mining

Berikut ini merupakan perhitungan manual Naive Bayes menggunakan dataset pasien pengidap kanker payudara yang diperoleh dari University Medical Center. Data sudah di preprocessing sehingga menghasilkan data dengan jumlah 186 records.

\begin{tabular}{|c|c|c|c|c|c|c|c|c|}
\hline Class Age & Menopause & Tumor-size & Inv-nodes & Node-caps & Deg-malig & Breast & Breast-quad & Irradiant \\
\hline no-recurre 30.39 & premena & $30-34$ & $0-2$ & no & & left & left low & no \\
\hline no-rocurri $40-49$ & premeno & $20-24$ & 0.2 & no & & right & right_up & no \\
\hline no-recurri $40-49$ & premeno & $20-24$ & $0-2$ & no & & Jeft & left_low & no \\
\hline no-recurri $60-69$ & gease & $15-19$ & $0-2$ & no & 2 & fight & left_up & no \\
\hline no-recurri $40-49$ & premeno & $0-4$ & $0-2$ & no & 2 & right & rieht_low & no \\
\hline no-recurrite0-69 & Eeso & $15-19$ & $0-2$ & no & 2 & left & left_low & no \\
\hline no-recurriso-sy & premeno & $25-29$ & $0-2$ & no & & left & left_low & no \\
\hline no-recurric0-69 & geso & $20-24$ & 0.2 & no & 1 & left & left low & no \\
\hline no-recurre $40-49$ & premeno & $50-54$ & 0.2 & no & 2 & left & left, low & no \\
\hline no-recurr: $40-49$ & premeno & $20-24$ & 0.2 & no & 2 & right & left_op & no \\
\hline no-recurri $40-49$ & premeno & 0.4 & $0-2$ & no & 3 & iett & central & no \\
\hline no-recurriso-sy & gesto & $25-29$ & $0-2$ & no & 2 & left & left_low & no \\
\hline no-tecurru $50-50$ & geto & $25-29$ & $0-2$ & no & 3 & left & right_up & no \\
\hline no-recurri $40-49$ & premeno & $30-34$ & $0-2$ & no & 3 & left & left_up & no \\
\hline no-recurrico-69 & $1+40$ & $30-34$ & $0-2$ & no & 1 & left & left Jlow & no \\
\hline no-recurre $40-49$ & premeno & 15.19 & 0.2 & no & & left & left low & no \\
\hline no-recurriso-59 & premeno & 30.34 & 0.2 & no & 3 & left & left_low & no \\
\hline no-rocurru $60-69$ & $g \in 40$ & $30-34$ & 0.2 & no & 3 & left & left_low & no \\
\hline no-recumso-s9 & $g 040$ & $30-34$ & $0-2$ & no & 1 & fight & right_up & no \\
\hline no-recurriso-s9 & gesto & $40-44$ & $0-2$ & no & & left & left_low & no \\
\hline no-recurrio0-69 & gesto & $15-13$ & $0-2$ & no & 2 & left & left_low & no \\
\hline no-recurre $30-39$ & oremeno & $25-29$ & $0-2$ & no & & rieht & left low & no \\
\hline
\end{tabular}

Gambar 2. Data yang sudah melalui tahapan preprocessing

Menghitung jumlah kelas berdasarkan klasifikasi yang terbentuk (prior probability) :

1. $\mathrm{C} 1$ (Class $=$ "Kambuh") $=47 / 186=0,253$

2. $\mathrm{C} 2($ Class $=$ "Tidak Kambuh" $=139 / 186=0,747$

c. Menghitung Jumlah Kasus yang Sama pada Setiap Atribut dari Class (Kambuh/Tidak Kambuh) Berdasarkan Data Testing

\begin{tabular}{|c|c|c|}
\hline Class & Age & $|\boldsymbol{s}|_{1}$ \\
\hline no-recurrence events & $50-59$ & \\
\hline no recurrence events & 5059 & \\
\hline no rocurrence-ovents & 50.59 & \\
\hline no-rocurrence-ovonts & $50-59$ & \\
\hline no-recurrence-events & $50-59$ & 1 \\
\hline no-recurrence-pvents & $50-.59$ & \\
\hline no-recurrence-events & $50-59$ & 1 \\
\hline no-recurrence-events & $50-59$ & I \\
\hline no-recurrence-events & $50-59$ & I \\
\hline no-recurtence-events & 50-59 & 1 \\
\hline no-recurrence-events & $50-59$ & 1 \\
\hline no-recurrence-events & $50-59$ & 1 \\
\hline no-recurrence-events & $50-59$ & \\
\hline no recurrence events & 5059 & \\
\hline no-recurrence-events & 50.59 & 1 \\
\hline no-rocurronce-ovents & $50-59$ & \\
\hline
\end{tabular}

Gambar 3. Contoh kasus

1. $\mathrm{P}($ Age $=$ "50-59" $\mid$ Class $=$ "Kambuh" $)=11 / 47=0,243$

2. $\mathrm{P}(\mathrm{Age}=$ "50-59" $\mid$ Class $=$ "Tidak Kambuh" $)=51 / 139=0,367$

(Hitung probabilitas dari keseluruhan atribut data seperti contoh di atas).

d. Kalikan Semua Hasil Variabel

Klasifikasi studi kasus semua variabel : 
Age $=\mathbf{5 0 - 5 9}$, Menopouse $=$ ge40, $\mathrm{T}-\mathrm{S}=\mathbf{3 0 - 3 4}, \mathrm{I}-\mathrm{N}=\mathbf{0 - 2}$, Nod-C $=$ yes, $\mathrm{D}-\mathrm{M}=\mathbf{3}$, Breast $=$ left, Breast-quad $=$ left-low, Irr $=$ yes.

a. Untuk semua atribut Class = "Kambuh"

$\mathrm{P}(\mathrm{X} \mid$ Class = "Kambuh")

$=0,234 \times 0,319 \times 0,234 \times 0,915 \times 0,149 \times 0,447 \times 0,489 \times 0,383 \times 0,234$

$=0,0000467$

b. Untuk semua atribut Class = "Tidak Kambuh"

$\mathrm{P}(\mathrm{X} \mid$ Class $=$ "Tidak Kambuh")

$=0,367 \times 0,489 \times 0,187 \times 0,978 \times 0,058 \times 0,223 \times 0,532 \times 0,367 \times 0,122$

$=0,0000101$

c. Perkalian prior probability dengan semua atribut Class = "Kambuh"

P (Ci) | Class = "Kambuh" x P (X | Class = "Kambuh")

$=0,253 \times 0,0000467$

$=0,000012$

d. Perkalian prior probability dengan semua atribut Class = "Tidak Kambuh"

P (Ci) $\mid$ Class = "Tidak Kambuh" x P (X | Class = "Tidak Kambuh")

$=0,747 \times 0,0000101$

$=0,000008$

e. Bandingkan Hasil Kelas

P (Ci) $\mid$ Class = "Kambuh" x P (X | Class = "Kambuh") > P (Ci) $\mid$ Class = "Tidak Kambuh" x P (X | Class = "Tidak Kambuh")

Kesimpulan :

Class $=$ "Kambuh"

(Perhitungan antara perkalian Class "Kambuh" dengan Class "Tidak Kambuh" menunjukkan bahwa nilai Class = "Kambuh" lebih besar dibandingkan nilai Class = "Tidak Kambuh").

f. Implementasi Menggunakan RapidMiner

Berikut ini merupakan proses pengolahan dataset menggunakan RapidMiner dengan metode Naive Bayes.

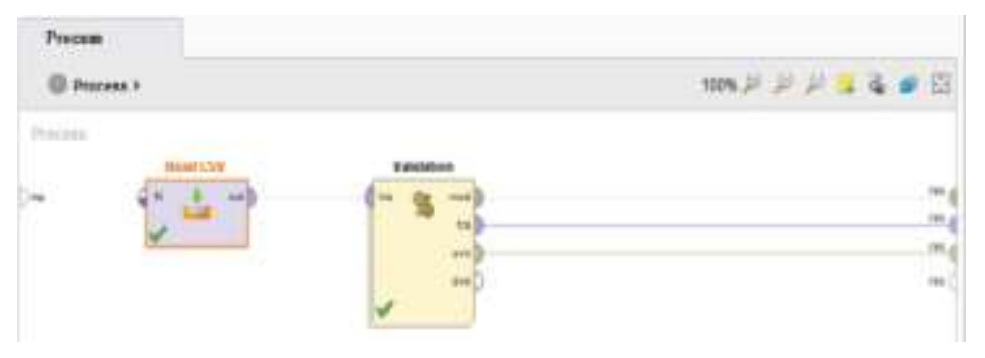

Gambar 4. Pemodelan menggunakan RapidMiner

1. Pemodelan merupakan tahap dalam membuat model berdasarkan sistem nyata (realitas)

2. RapidMiner adalah tools yang berfungsi untuk machine learning, text mining serta predictive analytics.

3. Dataset awalnya berjumlah 286 records data, setelah dilakukan preprocessing data jumlah records berkurang menjadi 186. Peneliti menggunakan RapidMiner untuk membantu proses perhitungan.

4. Split Validation untuk membantu menghasilkan tingkat keakurasian berdasarkan dataset yang sudah dilakukan klasifikasi sebelumnya

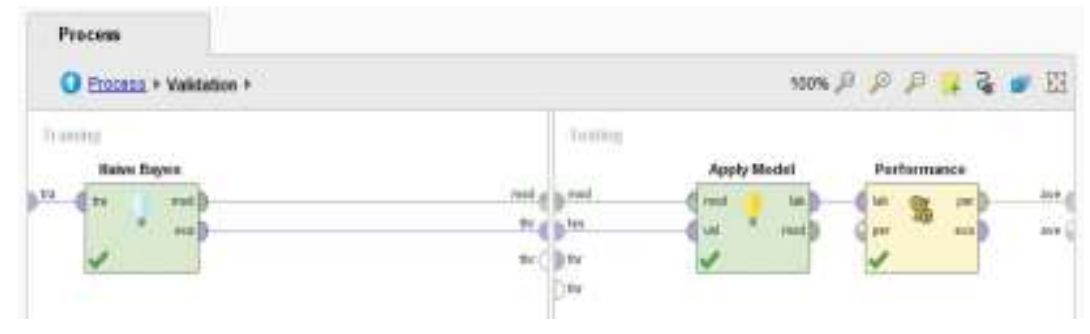

Gambar 5. Split Validation pada RapidMiner 
Tujuan utama dilakukannya penelitian ini adalah untuk mengetahui nilai akurasi dari pemodelan menggunakan algoritma Naive Bayes dengan tools yang digunakan yaitu RapidMiner. Pola data baru yang dihasilkan digunakan untuk proses klasifikasi pasien pengidap kanker payudara.

Dalam kolom training terdapat algoritma yang digunakan yaitu Naive Bayes. Sedangkan dalam kolom testing, terdapat operator Apply Model yang berfungsi untuk menjalankan model Naive Bayes serta Performace yang berfungsi untuk mengukur performa dari model Naive Bayes yang digunakan tersebut.

g. Hasil Pengujian dan Percobaan

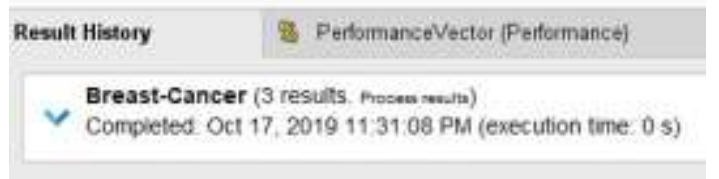

\section{Gambar 6. Contoh result history pada RapidMiner}

Pada percobaan pengolahan dataset dengan algoritma Naive Bayes dibantu tools RapidMiner, diperoleh waktu eksekusi proses yaitu 0 detik. Hal ini membuktikan bahwa perhitungan menggunakan Naive Bayes berjalan sangat cepat. Kelebihan Naive Bayes salah satunya yaitu waktu komputasi yang lebih singkat jika dibandingkan algoritma lain seperti neural network yang membutuhkan waktu lebih lama.

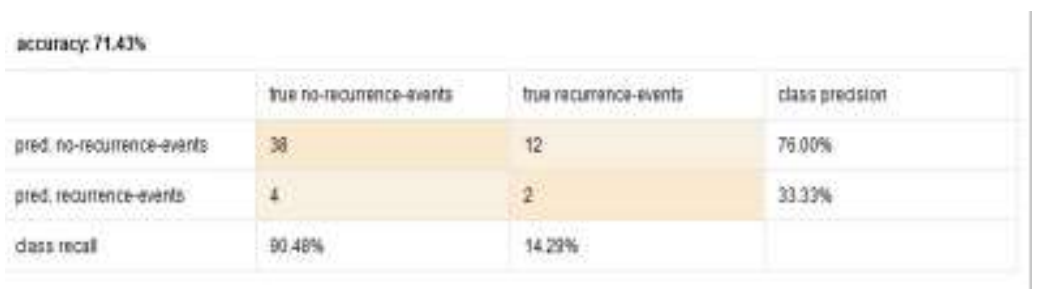

Gambar 7. Nilai akurasi menggunakan Naive Bayes

Hasil akurasi perhitungan menggunakan algoritma Naive Bayes menunjukan persentase nilai sebesar $71,43 \%$. Artinya mencari nilai akurasi menggunakan algoritma ini cukup baik berdasarkan tingkat akurasinya yang mencapai $70 \%$ lebih. Hanya saja tetap harus mempertimbangkan hal-hal lain dalam proses perhitungan nilai akurasi seperti kompleksitas dan jumlah datasetnya.

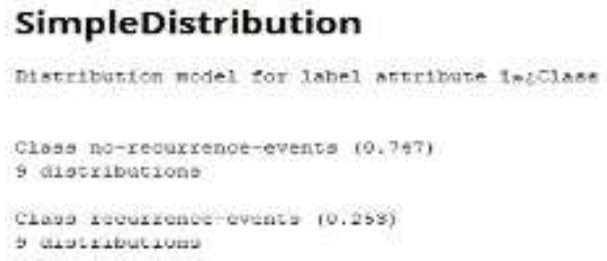

Gambar 8. Simple Distribution

Model distribusi untuk label atribut Class adalah sebagai berikut :

1. Class "Tidak Kambuh" : 9 distributions

2. Class "Kambuh" : 9 distributions

Percobaan pada penelitian ini menggunakan Rapidminer 9.3. Algoritma yang digunakan adalah Naive Bayes. Validasinya menggunakan $x$-validation dan untuk testing menggunakan Apply Model untuk menjalankan algoritma atau model Naive Bayes serta Performance untuk mengukur performa dari model Naive Bayes tersebut.

\subsection{Evaluasi}

Evaluasi merupakan fase di mana peneliti melakukan kontrol terhadap pemodelan yang sudah dilakukan agar mendapatkan hasil yang sesuai dengan sasaran yang ingin dicapai pada tahap pemahaman bisnis. Fase ini merupakan fase lanjutan yang lebih mendalam terhadap tujuan data mining.

a. Evaluasi Hasil

Tahap ini berfungsi untuk menilai sejauh mana hasil pemodelan data mining dapat memenuhi tujuan data mining yang sudah ditetapkan pada tahap pemahaman penelitian.

b. Pengecekan Ulang Proses

Pemodelan yang sudah dilakukan dan sudah dievaluasi kemudian dilakukan pengecekan ulang agar faktor-faktor penting yang berpengaruh dalam proses pengolahan data tidak terlewatkan. 
c. Menentukan Langkah Selanjutnya

Tahap ini peneliti merencanakan kembali tahap selanjutnya yang harus dilakukan. Ada 2 pilihan yang dapat dilakukan, pertama kembali ke tahap awal yaitu ke tahap pemahaman bisnis. Kedua yaitu melanjutkan ke tahap selanjutnya yaitu tahap persebaran (tahap akhir).

\subsection{Persebaran}

Persebaran merupakan tahap akhir dari sebuah proses data mining. Pada tahap ini dibuat suatu laporan akhir yang berisi tentang pengetahuan yang diperoleh atau pengenalan pola pada data dalam proses data mining.

Pada penelitian yang dilakukan, telah dihasilkan suatu pola data atau informasi baru dalam proses data mining untuk klasifikasi pengidap kanker payudara berdasarkan dataset yang diperoleh dari University Medical Center. Pola informasi yang dihasilkan sesuai dengan tujuan data mining yaitu pola perhitungan data mining yang berisi data training dan data testing serta mencari probabilitas dari setiap atribut data berdasarkan data training dan data testing untuk menghasilkan informasi baru. Pertanyaannya, apakah dari data yang diperoleh dari University Medical Center mengenai pasien pengidap kanker payudara, lebih besar probabilitas penyakit tersebut kambuh atau tidak kambuh?. Untuk menguji tingkat akurasinya sendiri, peneliti melakukan perhitungan dengan bantuan RapidMiner untuk menguji seberapa besar akurasi perhitungan dari klasifikasi tersebut. Berdasarkan proses perhitungan data mining menggunakan algoritma Naive Bayes, menghasilkan perkalian prior probabality dengan Class = "Kambuh" sebesar 0,000012, sedangkan perkalian prior probability dengan Class = "Tidak Kambuh" sebesar 0,000008. Dari segi tingkat akurasi, proses data mining menggunakan algoritma Naive Bayes dengan proses klasifikasi menghasilkan nilai akurasi perhitungan sebesar 71,43\% tentunya dengan melalui semua tahapan yang diperlukan dalam proses data mining.

Kesimpulan yang dapat ditarik dari hasil penelitian di atas yaitu pasien pengidap penyakit kanker yang mengalami kambuh penyakit masih lebih besar dibandingkan dengn pasien yang tidak mengalami kambuh. Analisa yang dilakukan menggunakan Naive Bayes sendiri menunjukan keakuratan perhitungan yang cukup besar dilihat dari persentase yang mencapai $70 \%$ lebih. Nilai 71,43\% bisa juga disebabkan oleh kekurang kompleksan data yang mengakibatkan model dapat memprediksi secara akurat.

\section{KESIMPULAN}

Berdasarkan perhitungan data mining menggunakan algoritma Naive Bayes, dapat ditarik kesimpulan bahwa Class pasien "Kambuh" lebih besar dibandingkan Class pasien "Tidak Kambuh". Akurasi terhadap klasifikasi data yang sudah dilakukan sebelumnya menggunakan algoritma Naive Bayes, diperoleh nilai akurasi terhadap pasien yang mengalami kambuh atau tidak sebesar 71,43\% di mana hal ini juag bisa disebabkan oleh kekurang kompleksan data sehingga model dapat memprediksi secara akurat.

Peneliti telah melakukan pembahasan menggunakan algoritma Naive Bayes mengenai pasien pengidap kanker payudara. Diharapkan pada penelitian selanjutnya dapat menggunakan algoritma lain seperti C.4.5 atau Nearest Neighbor guna memnetukan kelas berdasarkan atribut-atribut yang telah ditentukan sebelumnya sehingga dapat diketahui metode mana yang nilai akurasinya lebih baik melalui perbandingan berbagai metode. Pengklasifikasian data pasien yang mengalami kambuh penyakit kanker payudara atau yang tidak kambuh sebaiknya rutin dilakukan sebagai langkah pencegahan serta penangan untuk mengurangi jumlah pasien yang mengalami kambuh penyakit, sehingga penangan pasien pengidap kanker payudara dapat dilakukan secara optimal.

\section{REFERENCES}

[1] E. Turban, T.-P. Liang, and J. E. Aronson, Decision Support Systems and Intelligent Systems:(International Edition). Pearson Prentice Hall, 2005.

[2] D. T. Larose and D. T. Larose, Data mining methods and models, vol. 2. Wiley Online Library, 2006.

[3] Y. S. Nugroho, "Data Mining Menggunakan Algoritma Naive Bayes Untuk Klasifikasi Kelulusan Mahasiswa Universitas Dian Nuswantoro," Dian Nuswantoro Fak. Ilmu Komput. Skripsi, 2014.

[4] E. Prasetyo, "Data mining konsep dan aplikasi menggunakan matlab," Yogyak. Andi, 2012.

[5] C. Vercellis, Business intelligence: data mining and optimization for decision making. Wiley Online Library, 2009. 